\title{
Trueness and precision of the reproduction of dental casts by the conventional, milling and 3D printing techniques
}

Fidelidade e precisão de modelos de trabalho reproduzidos pelas técnicas convencional, de fresagem e de impressão 3D

Diogo Miguel da Costa Cabecinha Pacheco VIEGAS ${ }^{1}$ @ , Joana Raquel Lima HERMÍnIO ${ }^{2}$, João Pedro FERNANDES ${ }^{3}$,

Fernando ARROBAS ${ }^{2}$, Joao Carlos ROQUE ${ }^{1}$, João Tiago Cardoso Gonçalves MOURÃO ${ }^{1}$,

Guilherme de Siqueira Ferreira Anzaloni SAAVEDRA ${ }^{1,4}$

1 - Universidade de Lisboa, Faculdade de Medicina Dentária, Departamento de Prostodontia Fixa e Reabilitação Oral, Lisboa, Portugal.

2 - Universidade de Lisboa, Faculdade de Medicina Dentária, Lisboa, Portugal.

3 - Escola Superior de Saúde Egas Moniz, Monte da Caparica, Portugal.

4 - Universidade de São Paulo, Instituto de Ciências e Tecnologias, Departamento de Materiais Dentários e Prostodontia, São José dos Campos, SP, Brazil.

\begin{abstract}
Objective: To compare the reproduction trueness and precision of dental casts made by the conventional, milling and 3D printing techniques. Material and Methods: From an upper right side half-arch reference model (RM), 72 models were obtained and divided into three groups: conventional (CM), milled (MM) and printed (PM). All models were scanned and converted into standard tessellation language (.STL) files. The files were superimposed using 3D analysis software, and statistical analysis was performed using the root mean square (RMS) values obtained. The Shapiro-Wilk test was used to assess normality, and the Kruskal-Wallis test was used to compare groups $(\rho<\alpha ; \alpha=0.05)$. The Mann-Whitney $U$ test was used for multiple comparisons among groups $(\rho<\bar{\alpha} ; \bar{\alpha}=0.017)$. Results: There were significant differences in trueness $(\rho=0.000 ; \rho<0.001)$ and precision $(\rho=0.000 ; \rho<0.001)$ among the three dental cast groups. Regarding trueness, CM presented better results, followed by MM and PM. Regarding precision, MM showed better results, followed by PM and CM, which did not show significant differences. Conclusions: For dental cast reproduction the conventional technique has the best trueness and the milling technique has the best precision.
\end{abstract}

\section{KEYWORDS}

Trueness; Precision; Milling; 3D printing; Dental cast.

\section{RESUMO}

Objetivo: Comparar a fidelidade e precisão de reprodução de modelos de trabalho pelas técnicas convencional, de fresagem e de impressão 3D. Material e Métodos: A partir de um modelo de referência (MR) de uma hemiarcada superior direita, foram obtidos 72 modelos divididos em três grupos: convencionais (MC), fresados (MF) e impressos (MI). Todos foram digitalizados e convertidos sob a forma de ficheiros.STL (standard tesselation language). Os ficheiros foram sobrepostos utilizando um software de análise 3D, e através dos valores $R M S$ (raiz do valor quadrático médio) obtidos foi realizada a análise estatística. Para avaliação da normalidade foi utilizado o teste Shapiro Wilk e para a comparação entre grupos foi utilizado o teste Kruskal-Wallis $(\rho<\alpha ; \alpha=0.05)$. Para as comparações múltiplas entre grupos, foi utilizado o teste $U$ de Mann-Whitney $(\rho<\bar{\alpha}$; $\bar{\alpha}=0.017)$. Resultados: Existem diferenças significativas de fidelidade $(\rho=0.000 ; \rho<0.001)$ e precisão $(\rho=0.000 ; \rho<0.001)$ entre os três grupos. Em relação à fidelidade, MC apresentou melhores resultados, seguido por MF e MI. Em relação à precisão, MF apresentou melhores resultados, seguido por MI e MC, que não apresentaram diferenças significativas entre si. Conclusão: Para reprodução de modelos de trabalho, a técnica convencional é a que apresenta maior fidelidade e a técnica de fresagem a que apresenta maior precisão.

\section{PALAVRAS-CHAVE}

Fidelidade; Precisão; Fresagem; Impressão 3D; Modelo de trabalho. 


\section{INTRODUCTION}

In recent years, digital workflows have shown exponential development in the field of dentistry[1-3]. This is due to the development of computer-aided design/computer-aided manufacturing (CAD/CAM) technology, which is divided into three components: digitalization of information, processing software and a production component that converts information into a physical object with predetermined characteristics $[2,4]$.

Compared to the conventional impression technique, digital impression has been found to be faster and more comfortable for the patient, and it presents a level of accuracy compatible with clinical needs[4-8]. The acquired information is organized in a 3D coordinate system[9]. In most cases, digital formatting uses an .STL (standard tessellation language) file[4,9].

Digital prosthodontics enables the 3D recreation of an individual model, digital or physical $[2,10]$. Dental casts are extremely important in the diagnosis and treatment plan for fixed prosthodontics, considering that adaptation is the main characteristic necessary to ensure rehabilitation success and that without a physical model, the adaptation between the abutment and the prosthetic piece cannot be evaluated before the prosthesis is inserted[4,11].

Producing physical models using digital technology is still an expensive process when compared to the conventional technique, but it has the great advantage of reducing the risk of human error $[3,12]$. In digital dentistry, discrepancies from reality may arise with each procedure performed. For this reason, dimensional changes of up to $200 \mu \mathrm{m}$ are considered clinically acceptable; these are more evident in the $\mathrm{Z}$ axis of the 3D plane $[4,13,14]$.

Using the CAD/CAM system, physical dental casts can be fabricated by subtraction or addition by using milling or 3D printing techniques, respectively[2].

In subtraction, a block or disc of material is worn until the desired final geometry is achieved $[15,16]$. In contrast, the $3 \mathrm{D}$ printing method allows objects to be recreated via the deposition of layers of polymerizable material and can be based on several systems, such as stereolithography (SLA), triple jetting technology (PolyJet) or digital light processing (DLP) [17-22].
This technique has the advantages of lower material consumption - material use is reduced by approximately $40 \%$ compared to the subtraction technique, and approximately $95 \%$ to $98 \%$ of the remaining material can be recycled[12]. It also allows the reproduction of several elements at the same time, thus making clinical and laboratory practice more efficient[1].

Accuracy is expressed in terms of trueness and precision. Trueness represents how close the actual value is to the supposed value, while precision represents the closeness of repeated actual measurements to the supposed value $[4,23]$. There is some disagreement in the literature regarding the accuracy of dental casts reproduced using the digital milling technique:

In a study comparing the accuracy of dental casts reproduced using the conventional and milling techniques, models of an individual tooth were evaluated; the conventional technique showed better results, and these differences were more significant for the occlusal surface[24].

In the comparison between conventional dental casts and dental casts printed using the SLA technique, some studies found greater accuracy associated with conventional plaster models[25-27]. In contrast, others did not find significant differences[28-30].

When conventional models and models printed using the SLA and PolyJet techniques were evaluated, it was found that the conventional method had better trueness and that the PolyJet technique had better precision[31]. Among conventional models and models printed using the DLP and PolyJet techniques, the conventional models showed better trueness and precision due to the smaller dimensional changes presented. However, among the 3D printing techniques, DLP with ultraviolet polymerization showed the best results[3].

When comparing milled and SLA-printed full-arch models, 3D printing showed superior accuracy[33]. In contrast, another study found the milling technique to be more reliable than the PolyJet technique[34]. A more recent study showed that printed models have greater trueness and precision than milled models; however, the results obtained raised questions regarding the applicability of these models in prosthodontics[35]. 
The reproduction accuracy of models fabricated by the conventional, milling, SLA and DLP techniques was also evaluated for inlay, crown, bridge and full-arch preparations. For full-arch reproduction, the conventional model showed greater accuracy, and the milling technique showed the best overall precision. Regarding trueness, similar results were obtained with all techniques for these preparations [36].

The literature confirms that milled and printed models show acceptable accuracy compatible with clinical practice for fixed prosthodontics in several situations: marginal adaptation of crowns on teeth [37-39], marginal adaptation of inlays [40], tooth-supported bridges[41,42], crowns on implants[43] and implant-supported bridges[44]. In all of these studies, the 3D printing technique showed the best precision and trueness, except in the case of the adaptation of inlays, where milling was the technique with the best accuracy[40].

The objective of this study was to compare the trueness and precision of the reproduction of dental casts by the conventional, milling and 3D printing techniques. The null hypothesis was that there are no significant differences in trueness among the conventional, milling or 3D printing methods used to obtain dental casts; and that there are no significant differences in precision among the conventional, milling or 3D printing methods used to obtain dental casts.

\section{MATERIAL AND METHODS}

\section{Production of the Reference Model (RM)}

As a reference, a model of an upper right side half-arch missing second pre-molar tooth and with the preparation of first pre-molar and first molar teeth for a three-unit bridge (Figure 1) was used. The model was milled in polymer (Model Blank Beige 95H39, ZirkonZahn GmbH, Bruneck, Italy; REF: 8526). From the RM, 72 models were obtained and were divided into three groups: 24 conventional models (CM), 24 milled models (MM) and 24 printed models (PM).

\section{Production of Conventional Models (CM) [n $=24]$}

The CMs were produced from $24 \mathrm{RM}$ impressions obtained by the two-step technique using polyvinylsiloxane material with fluid
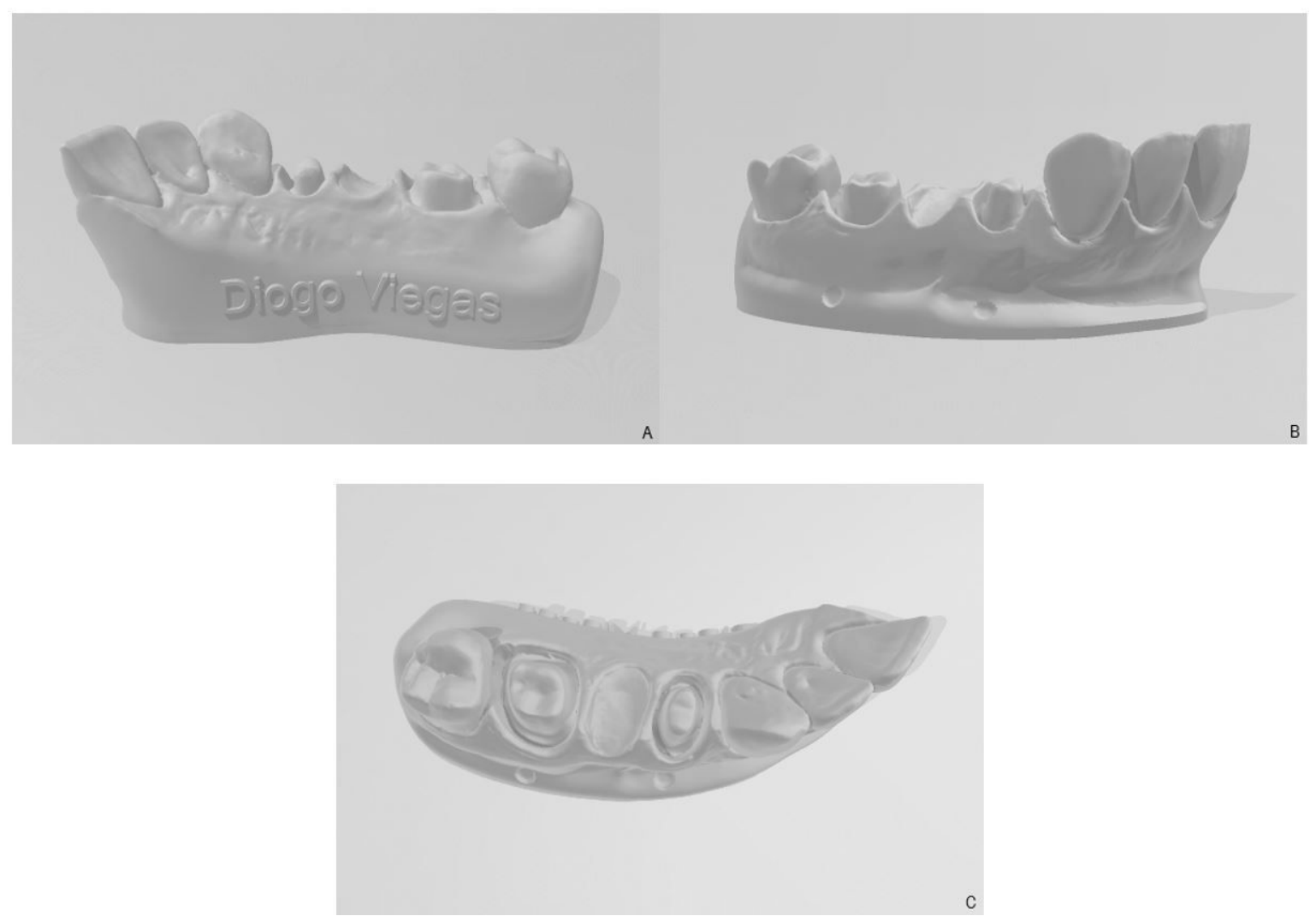

Figure 1 - Palatal (A), vestibular (B) and occlusal (C) views of the reference model. 
(Virtual, Ivoclar Vivadent, Schaan, Liechtenstein; REF: UL2299 / WL2324) and putty consistency (Virtual, Ivoclar Vivadent, Schaan, Liechtenstein; REF:WL2435) and a polymerization time of 4.5 minutes. Individual trays were prepared, obtained from an .STL file and impressed in resin (Dental SG, Formlabs, Inc., Massachusetts, USA; REF:XK221N04), as shown in Figure 2. An adhesive (VPS Tray Adhesive Refill, 3M ESPE, Minnesota, USA; REF:419032) was applied to increase the bond between the tray and the impression material.

After 1 hour, which is the manufacturerrecommended time required for the release of induced stresses and the elastic recovery of the impression material used, the moulds were filled with type IV plaster (Fujirock, GC Europe, Leuven, Belgium; REF: 1803284). Complete crystallization was allowed to proceed for 1 hour. The plaster models were separated from the impressions with a single laterolateral movement and stored for 48 hours at room temperature until analysis.

\section{Production of Milled Models (MM) [n = 24]}

A digital impression of the RM was made with a TRIOS 3 scanner (3Shape A/S, Copenhagen, Denmark), that was shown to be the most accurate scanner in a previous study[45], and the information was converted into an .STL file. The MMs were fabricated with a M4 milling machine unit (ZirkonZahn $\mathrm{GmbH}$, Bruneck, Italy; Figure 3) in polymer (Model Blank Beige 95H24, ZirkonZahn GmbH, Bruneck, Italy; REF:12958) with $2 \mathrm{~mm}, 1 \mathrm{~mm}$, $0.5 \mathrm{~mm}$ and $0.3 \mathrm{~mm}$ burs.
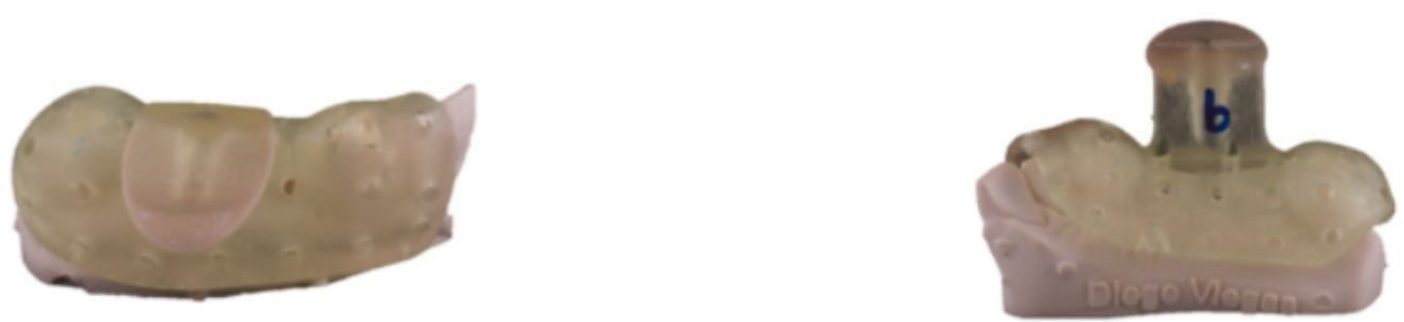

Figure 2 - Vestibular (A) and palatal (B) views of an individual tray made using the reference model.

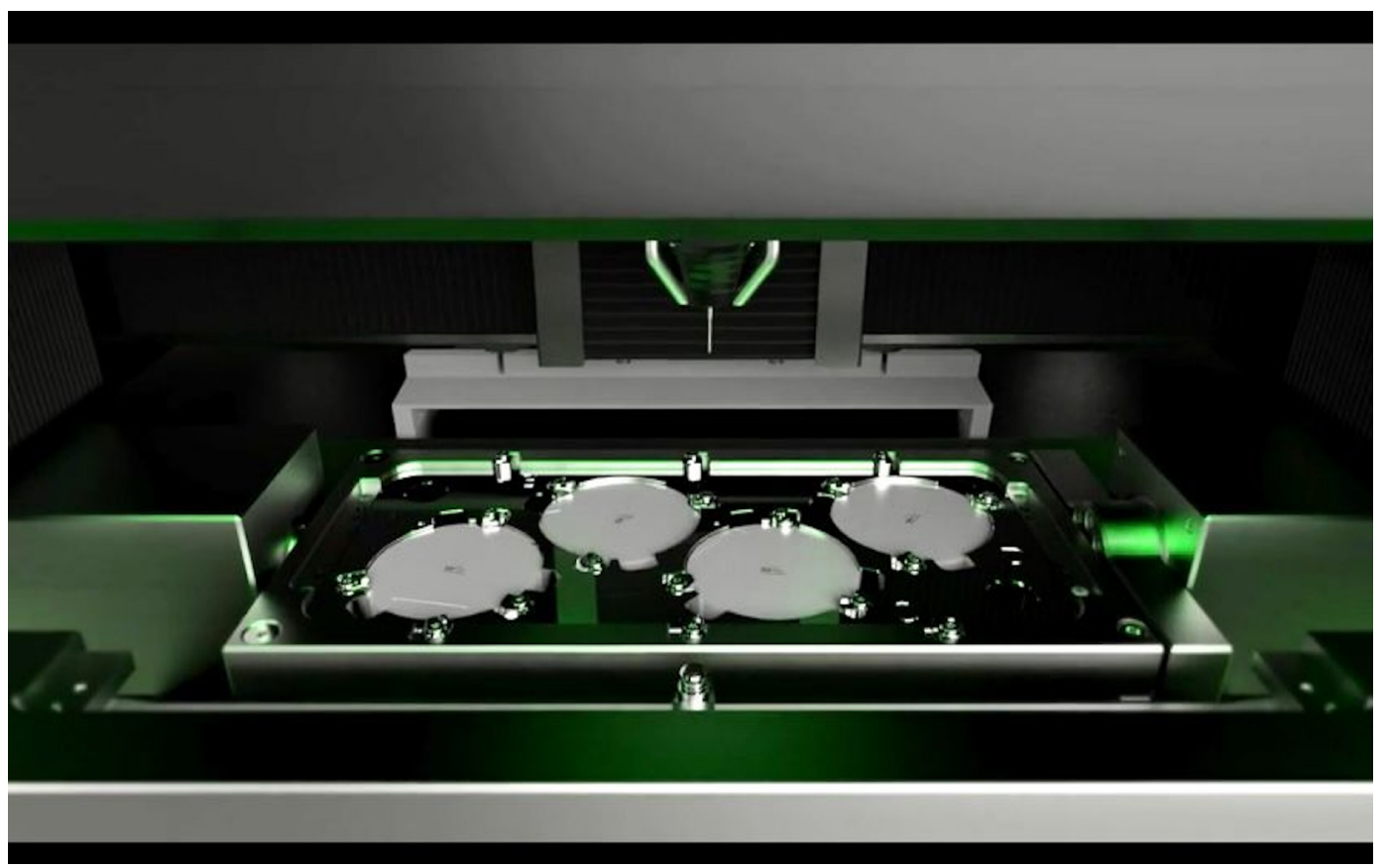

Figure 3 - Representative image of the M4 milling unit (ZirkonZahn GmbH, Bruneck, Italy) used in this study. Available at https://www. zirkonzahn.com/en/cad-cam-systems/milling-unit-m4. Access September 2020. 


\section{Production of Printed Models (PM) [n $=24]$}

To produce the PM, the aforementioned .STL file obtained from the digital impression of the RM was used. The models were prepared using a Form 2 printer (Formlabs, Inc., Massachusetts, USA), shown in Figure 4, which uses SLA technology with a computer-controlled moving laser beam, pre-programmed to produce $50 \mu \mathrm{m}$ resin layers (White V4 resin, Formlabs, Inc., Massachusetts, USA; REF:RS-F2-GPWH-04), cured by UV light (405nm).

\section{D analysis}

To standardize the measurements, all reproduced models were digitized with the aid of a laboratory scanner (S600 Arti, ZirkohnZahn $\mathrm{GmbH}$ ) and converted into .STL files, standard for CAD/CAM data exchange format[25-27]. The calibration of the scanner was performed by applying a standard calibration plaque and selecting the option "Calibrate scan" on ZirkohnZahn Scan software (ZirkohnZahn $\mathrm{GmbH}$ ) according to the manufacturer recommendations[45].

STL records were converted into point cloud data and then superimposed one to the other by computing all possible orientations and selecting the one with the best object-to-object penetration (best-fit alignment), as depicted in Figure 5.

The 3D discrepancy in the $\mathrm{x}$-, $\mathrm{y}$-, and z-axes among the data sets was analyzed using the 3D analysis software (3D Systems, Rock Hill, Sacramento, USA) which uses best-fit algorithms to superimpose and then compare data. The bestfit alignment command was applied for accurate alignment. For 3D analysis, the distances between surface of the virtual reference object and all points of the test objects were converted to

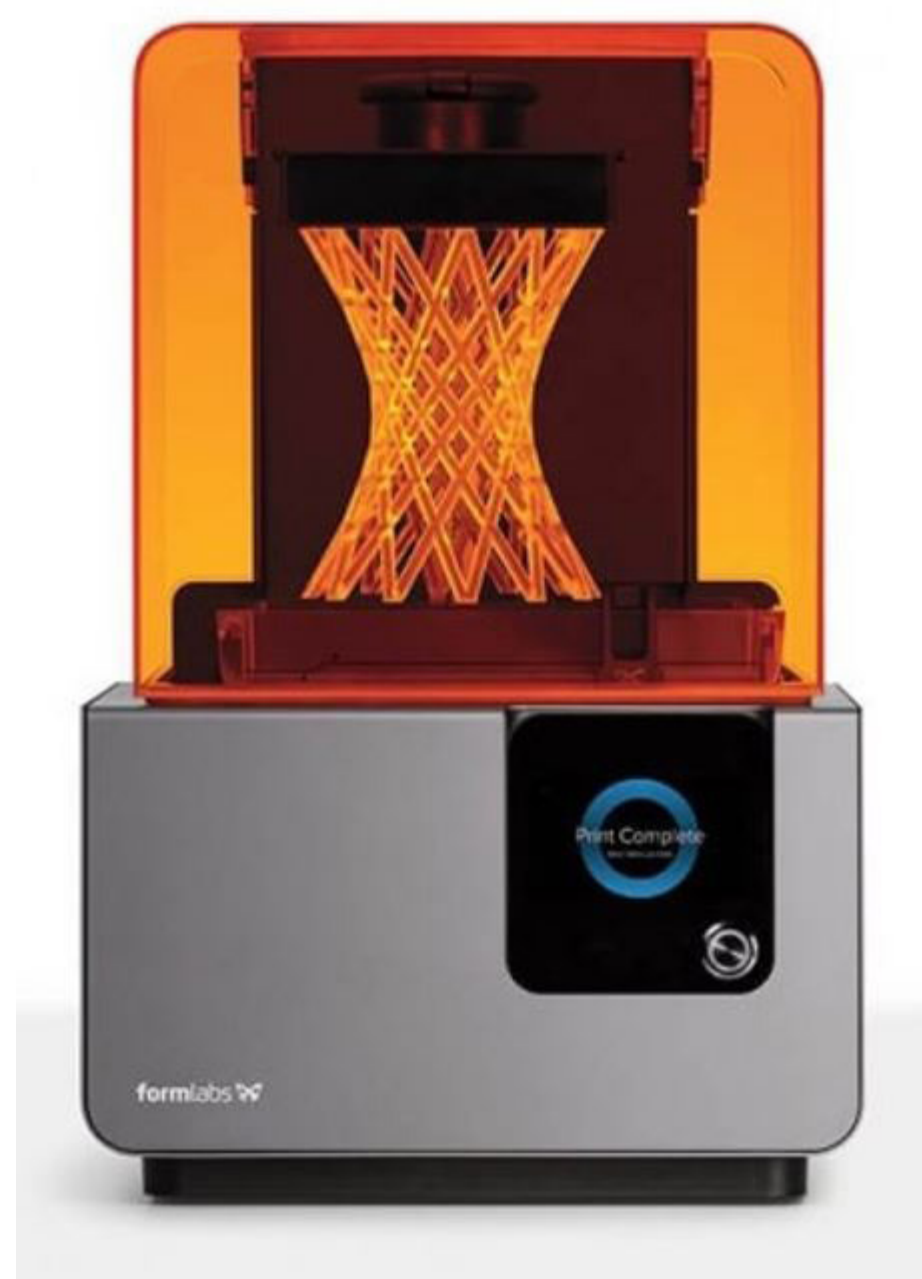

Figure 4 - Representative image of the Form 2 printer (Formlabs, Inc., Massachusetts, USA) used in this study. Available at https://formlabs. com/3d-printers/form-2/. Access September 2020. 


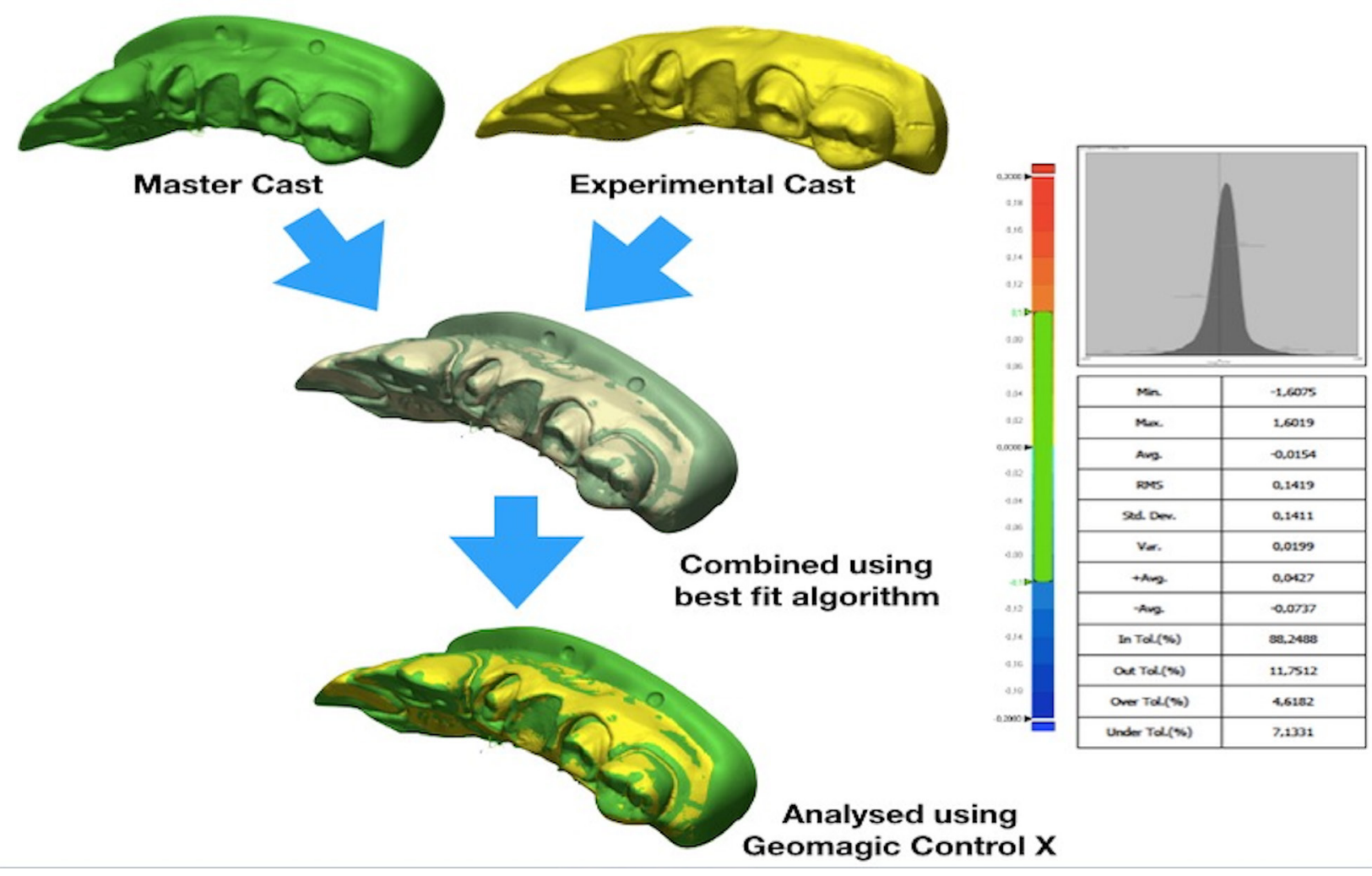

Figure 5 - Representation of the digital model analysis method with Geomagic Control X software (Mennito et al. 2018).

root mean square (RMS) values by the formula RMS $=\frac{1}{\sqrt{n}} \cdot \sqrt{\sum_{i=1}^{n}\left(x_{1, i}-x_{2, i}\right) 2}$, where $x_{1, \mathrm{i}}$ is measuring point $\mathrm{i}$ on reference, $x_{2, \mathrm{i}}$ is measuring point $i$ on duplicate, and $n$ is the total number of measuring points per specimen[31,36,41].

The quantitative values used for the analysis were extracted based on the RMS values, which represent the square root of the mean of the dimensional changes [31,36]. RMS is a recognized variable used to measure differences between superimposed 3D structures and is a general method to assess the mean value of errors, by directly comparing two data groups with an identical coordinate system [25-27,31,36,41]. Thus, a high RMS value indicates a large difference between the superimposed data sets, and a low RMS value indicates a high similarity[25,31]. There for the trueness and precision of a corresponding data group can be calculated using a single scale[41].

The trueness was evaluated by overlapping the RM file with the CM, MM and PM files individually, and precision was evaluated by overlapping the files within each group.

\section{Statistical analysis}

Regarding sample size, it was estimated through power analysis as it is a recurring approach in statistical theory[46]. Given the researchers' experience and the literature review, the decision was to perform an a priori calculation of the sample size considering a large effect size for the Anova-one-way test $(\mathrm{f}=0.40)$ [47]. These calculations were performed using the software G-Power*[48].For a minimum test power (1- $\beta$ ) of 0.8 and an $\alpha$ significance level of 0.05 , the minimum sample size for the comparison of three groups would be 66 observations (22 in each group). Our sample size was 72 (24 in each group).

The Shapiro-Wilk test was used to evaluate the normal distribution of the results, and the Kruskal-Wallis test was used to compare the groups. The significance level was defined as $\rho<\alpha$, where $\alpha=0.05$.

The Mann-Whitney U test was used for multiple comparisons among groups. Bonferroni correction was performed, after which $\bar{\alpha}$ assumed the value of 0.017 ; therefore, the significance level of this test decreased and was defined as 
$\rho<0.017$. The effect size (r) was also calculated using the equation $r=\frac{z}{\sqrt{(n)}}$.

The statistical data were processed and analysed using IBM SPSS Statistics 23 (SPSS, Inc., Chicago, IL, USA).

\section{RESULTS}

The three groups were analysed and compared in terms of trueness and precision.

\section{Trueness}

The descriptive statistics, assessment of normality and hypothesis tests related to trueness are shown in Table 1 and Figure 6.

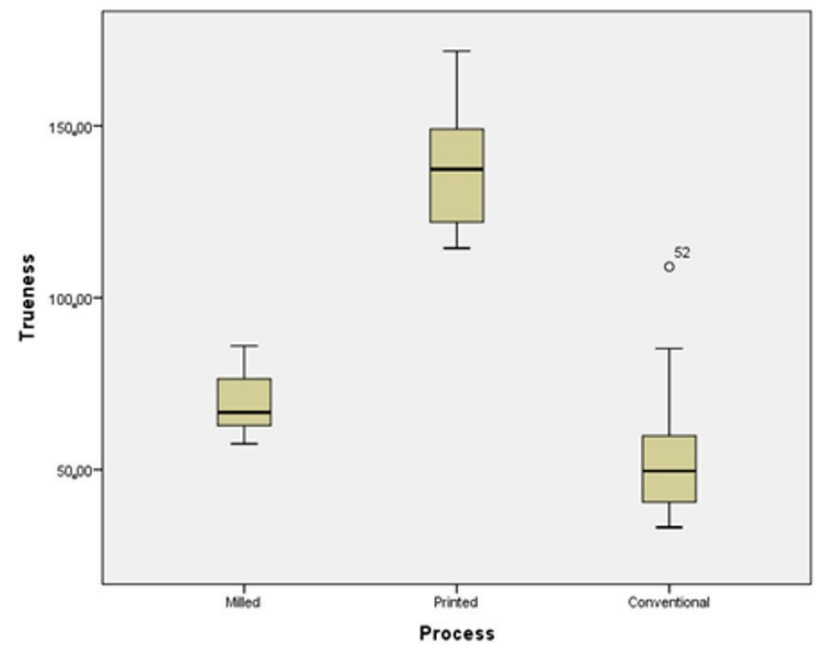

Figure 6 - Boxplots of trueness by process type.
Regarding normality, the Shapiro-Wilk test indicated that the distribution of the results was not normal only in the CM group $(\rho<\alpha)$. The KruskalWallis test revealed significant differences among the three groups $(\rho<0.001)$, with $\mathrm{CM}$ showing the best trueness.

The Mann-Whitney U test was used for trueness intergroup comparisons, and the results are described in Table 2.

A significant difference was found between $\mathrm{CM}$ and MM, and CM had better results $(\rho<\bar{\alpha})$. There were also significant differences between $\mathrm{CM}$ and PM, with CM showing better trueness $(\rho<$ व). MM and PM also showed significant differences from each other, with MM showing the best results $(\rho<\bar{\alpha})$. All significant results showed a large effect size $(r>0.5)$.

\section{Precision}

Descriptive statistics and hypothesis tests related to precision are shown in Table 3 and Figure 7.

The results obtained for all groups indicating that the distribution of the results was not normal $(\rho<\alpha)$. The Kruskal-Wallis test revealed significant differences among the groups $(\rho<0.001)$, with MM showing the best results.

The Mann-Whitney U test was used for the precision intergroup comparison, and the results are described in Table 4.

Table 1 - Evaluation of the effect of process type on trueness

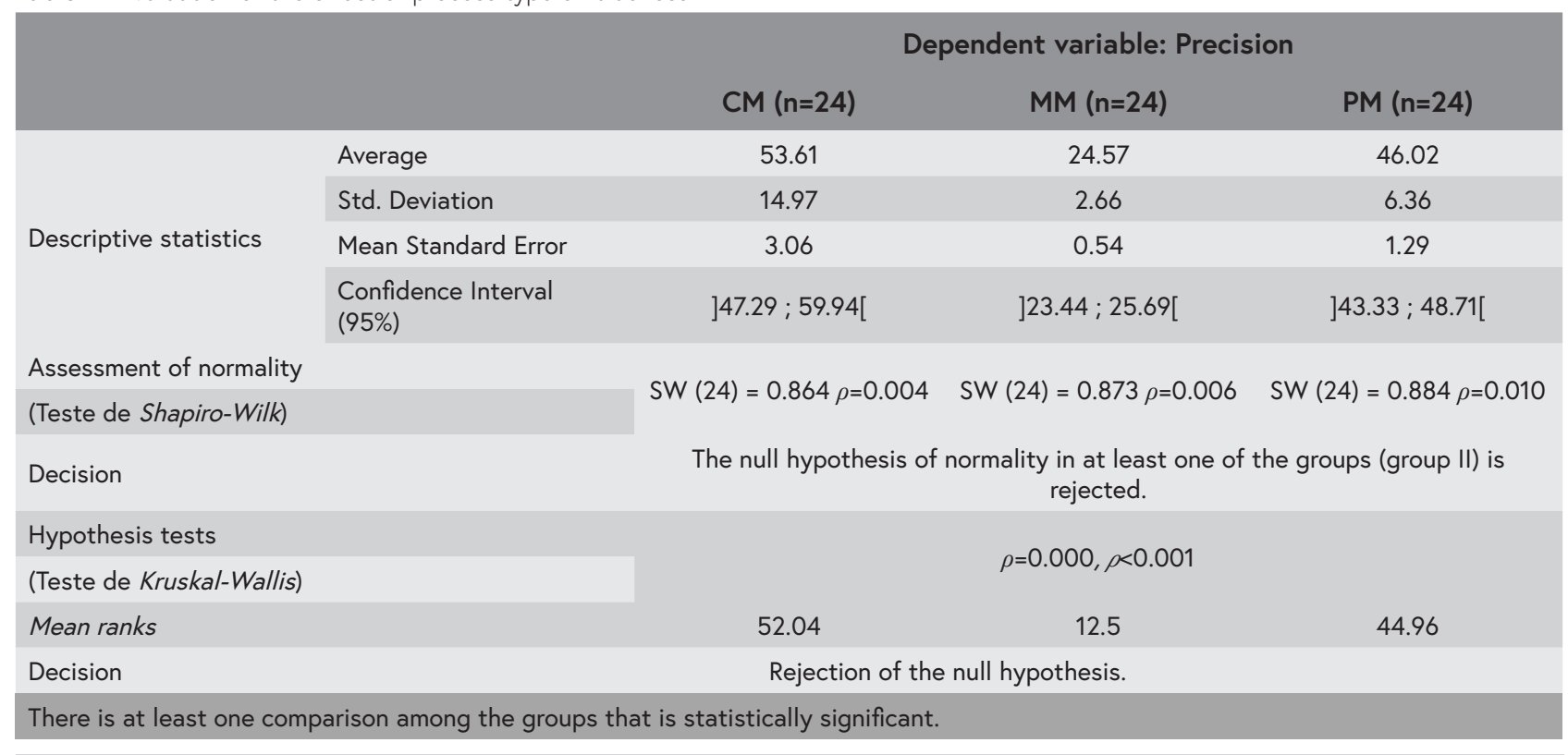


Table 2 - Evaluation of the effect of process type on trueness: multiple comparisons

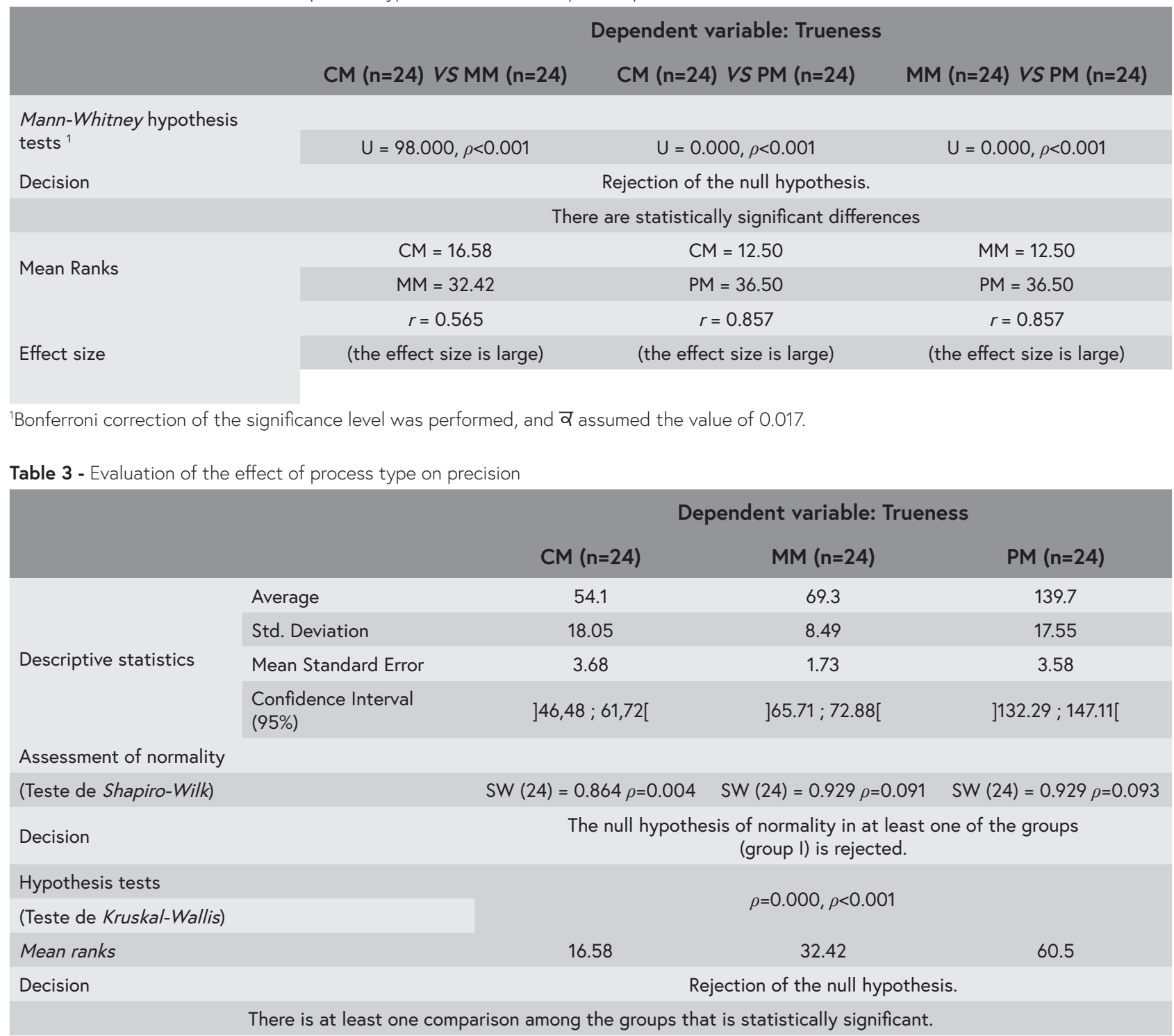

Table 4 - Evaluation of the effect of process type on precision: multiple comparisons

\begin{tabular}{|c|c|c|c|}
\hline & \multicolumn{3}{|c|}{ Dependent variable: Precision } \\
\hline & $C M(n=24)$ VS MM $(n=24)$ & CM $(n=24)$ VS PM $(n=24)$ & $M M(n=24)$ VS PM $(n=24)$ \\
\hline \multicolumn{4}{|c|}{ Mann-Whitney hypothesis } \\
\hline tests $^{1}$ & $U=0.000, \rho<0.001$ & $U=203.000, \rho=0.080$ & $U=0.000, \rho<0.001$ \\
\hline \multirow[t]{2}{*}{ Decision } & Rejection of the null hypothesis. & The null hypothesis is retained. & Rejection of the null hypothesis. \\
\hline & $\begin{array}{l}\text { There are statistically significant } \\
\text { differences }\end{array}$ & $\begin{array}{l}\text { There are no statistically } \\
\text { significant differences }\end{array}$ & $\begin{array}{l}\text { There are statistically significant } \\
\text { differences }\end{array}$ \\
\hline \multirow{2}{*}{ Mean Ranks } & $C M=36.50$ & $C M=28.04$ & $M M=12.50$ \\
\hline & $M M=12.50$ & $P M=20.96$ & $P M=36.50$ \\
\hline \multirow{2}{*}{ Effect size } & $r=0.857$ & $r=0.253$ & $r=0.857$ \\
\hline & (The effect size is large) & (The effect size is small) & (The effect size is large) \\
\hline
\end{tabular}

'Bonferroni correction of the significance level was performed, and $\mathbf{\alpha}$ assumed the value of 0.017 .

There were significant differences between $\mathrm{CM}$ and $\mathrm{MM}(\rho<\bar{\alpha})$, with MM showing greater precision. In contrast, there were no significant differences between. CM and PM $(\rho>$ व). There were significant differences between $\mathrm{MM}$ and $\mathrm{PM}$ $(\rho<$ व), with MM showing better results. Only the comparison between the CM and PM groups had a low effect size $(0.2 \leq r<0.5)$. 


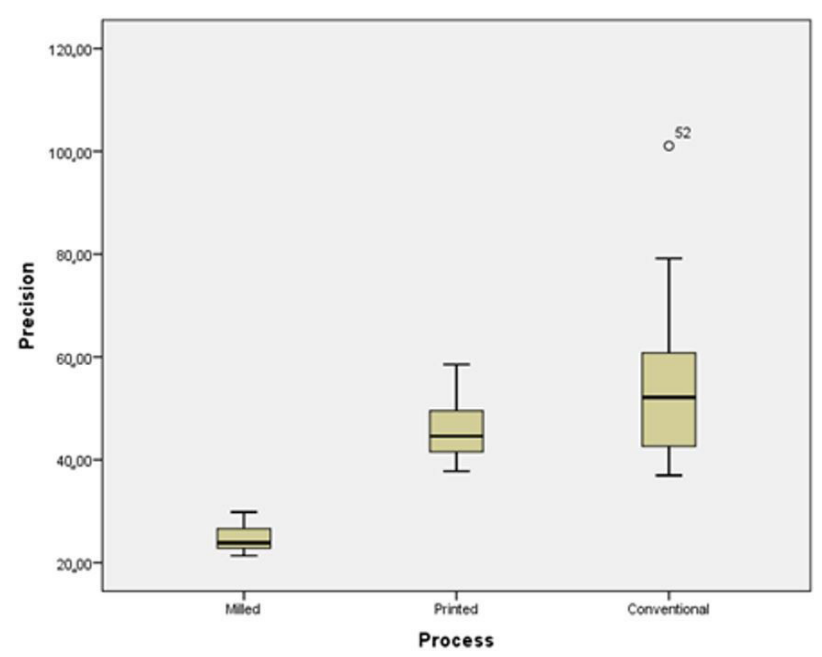

Figure 7 - Boxplots of precision by process type.

\section{DISCUSSION}

In this section, knowing that the null hypothesis was rejected, we analyse and discuss the results, taking into account the dependent and independent study variables and their possible combinations.

\section{Trueness}

Trueness represents the closeness between the mean value obtained from a series of test results and a reference value and can be influenced by systematic errors that depend mainly on the limitations of the work instruments, the technique used and the operator experience[23,49].

Thus, the crucial step for error propagation arises during data acquisition $[6,14]$. Videobased systems are considered more accurate; therefore, in this study, an ultrafast opticalsectioning system was used[9,14,33]. TRIOS 3 scanner (3Shape A/S, Copenhagen, Denmark), that was shown to be the most accurate scanner in a previous study, has a trueness of $6.9 \pm$ $0.9 \mu \mathrm{m}$ [50], a precision of $4.5 \pm 0.9 \mu \mathrm{m}$ [50] and a resolution of 41.21 points per $\mathrm{mm}[2,51]$ and considering that these scanner was only used to collect information from digital groups, we consider the possibility of a influence of the type of scanner on the results obtained[50].

In this study, the conventional technique showed significantly better trueness than the digital techniques of milling $(\rho<0.001)$ and 3D printing $(\rho<0.001)$. Kim et al.[24] validated the results obtained for the milling technique. Other studies also confirm the results obtained for the 3D printing technique[25,26,31,32].
In contrast, Sim et al.[27] and Choi et al.[36] did not find significant differences when comparing techniques.

In the conventional group, the impression material used was elastomer, which is currently considered the standard for diagnosis and treatment plans[33,36]. This type of material provides more detailed reproduction and dimensional stability[1,3,10,52]. Regarding the fabrication of the model, type IV plaster was used, which has low setting expansion and high fracture strength[53].

It is known that at each stage of the process of reproducing conventional models, the risk of human error increases, mainly because this technique involves greater manipulation by the operator and is dependent on his or her experience[1-8]. To counteract these influence, correct and careful handling of the materials according to the manufacturer's instructions was necessary[7,53].

According to the results obtained, although the milling technique presented lower results than the conventional technique, it was more reliable than the 3D printing technique $(\rho<0.001)$, and this difference was statistically significant. The study of Yau et al.[34] corroborates the results obtained; however, the same does not occur in other studies[33,35]. Similar contradiction can be observed in comparative studies on the adaptation of prosthetic pieces [37-44]; however, for inlays, which are small and highly detailed pieces, milling showed the best results[40].

With the milling technique, the shape and thickness of the drills and the ability of the unit to rotate an object are directly related to the trueness of the geometric shape fabricated[11-13,16]. In this study, a milling unit equipped with $5+1$ axes was used, thus obtaining greater accuracy $[3,15]$.

Regarding the 3D printing technique, an SLA printer was used that allows the polymerization of layers of material of uniform thickness using a UV laser beam[17-19]. Al-Imam et al.[26] found that the trueness of the printed models is directly related to the system used, and there were significant differences among models fabricated with different printers, but this was not observed regarding precision. According to Camardella et al. [30], dimensional changes relative to the reference model are mainly due 
to the associated polymerization shrinkage. Keating et al.[28] confirmed that these changes are greater in the Z plane[20,27-29]. According to Chockalingam et al.[22], a maximum thickness of $125 \mu \mathrm{m}$ is related to lower residual stress caused by the associated polymerization shrinkage (changes may vary between 6 and 10\%).

In addition to thickness, the acrylic resin used and its degree of conversion, the laser size and intensity and the final surface treatment procedures influence the cascade of errors that may be associated with the reproduction of objects by SLA[8,20-22]. In the present case, the finishing procedures recommended by the manufacturer involve using UV light and heat, thus improving the mechanical properties of the object. This process can enhance shrinkage and deformation[28].

\section{Precision}

Precision provides information on the degree of agreement of the individual measurement values of a dataset. It is therefore independent of the reference value. Thus, precision depends on the presence of random or accidental errors, which are influenced by the external conditions of repeatability and reproducibility $[23,49]$.

To reduce the probability of this type of error, data acquisition was performed extraorally to avoid distortions caused by the environment, such as the patient's movements and the presence of fluids $[5,7,8,33]$. The scanner that was used (S600 Arti, ZirkohnZahn $\mathrm{GmbH}$ ) has a precision $\leq 10 \mu \mathrm{m}$ [54], and the same scanner was used for data treatment for all groups, which excluded the possibility that it would have a negative influence on the results obtained.

In this study, the milling technique was found to be significantly more accurate than the conventional $(\rho<0.001)$ and 3D printing $(\rho<0.001)$ techniques. Yau et al.[34] obtained similar results, and when compared with other techniques, milling showed the best precision[36]. Patzelt et al.[33] obtained divergent results; however, the fact that a different scanner was used for each group may have influenced their results[14]. Jeong et al.[35] also contradicts the results obtained; however, they used a $100-\mu \mathrm{m}$-thick drill bit, and thus, the reproduction detail was lower. In addition, two models per block were reproduced as a way to reduce fatigue, which may have contributed to reduce the accuracy associated with the reproduction of the milled models[35].

The milling technique involves errors that can be caused by the physical contraction or expansion of the wearing instruments, their excessive vibration or bending due to the wear forces exerted, which reduces their effectiveness with each use[15,16].

In this study, although the conventional and the $3 \mathrm{D}$ printing techniques presented results that were inferior to those of the milling technique, they showed no significant differences in precision $(\rho>$ व). In the literature, some studies corroborate the results obtained[28-30]; however, some argue that the conventional technique has better precision than the 3D printing technique[25-27], and Jin et al.[31] obtained contradictory results.

To ensure precision and adequate long-term dimensional stability in dental casts reproduced by using the conventional technique, it is necessary to ensure an adequate and stable environmental temperature and correct mould disinfection, material packaging and elapsed time between phases $[52,53]$. The disregard of any of these conditions may explain the existence of an outlier in the data of this group and may have influenced the results obtained; however, we found that excluding this outlier would not affect the statistical results.

Regarding the 3D printing technique, Jin et al.[31] found that it had superior precision and that the PolyJet technique showed better results than the SLA technique, which was confirmed by Park and Shin[32]. Thus, we can infer that the printing method may have influenced the results obtained. Printed objects are also more sensitive to light, temperature and the presence of oxygen, so their storage conditions may have also been important $[17,30]$.

A strength of this study is that it had a relatively large sample size when compared with all identical studies found in the literature[33-44]. The models also were analysed using software to reduce the error associated with linear measurements; thus, a greater number of reference markers was used, which decreased the risk of bias[31,36].

In fixed prosthesis, a maximum accuracy of $70 \mu \mathrm{m}$ is used as the reference value to ensure that there is good adaptation between the prosthetic piece and the dental model, and a maximum value of $200 \mu \mathrm{m}$ between the dental model and the original is permitted[28,31,34]. 
Considering the RMS values obtained, we can state that the models reproduced in our study, both conventional and digital, had excellent clinical applicability in fixed prosthodontics.

This study had also limitations, including the fact that an artificial dental cast was used. Although this approach eliminated the risk of distortions associated with the oral environment, it did not make it possible to obtain exactly real values relative to those found in clinical practice. Additionally, differences in the methods used in different studies in the literature make it difficult to compare their results[5].

\section{CONCLUSIONS}

With this study, we can conclude that there are significant differences in trueness among dental casts reproduced using the conventional, milling or 3D printing methods. The conventional technique showed the best results.

We also conclude that there are significant differences in precision among dental casts reproduced using the conventional, milling or $3 \mathrm{D}$ printing methods. The milling technique showed the best results.

Considering the limitations of this study, we can state that, for reproduction of dental casts, the conventional technique offers the best trueness, and the milling technique offers the best precision. However, all casts reproduced in our study, both conventional and digital, had excellent clinical applicability in fixed prosthodontics.

\section{Acknowledgments}

The authors thanks DMTech for helping with the manufacturing the specimens.

\section{Conflict of Interest}

The authors have no proprietary, financial, or other personal interest of any nature or kind in any product, service, and/or company.

\section{Funding}

This research did not receive any specific grant from funding agencies in the public, commercial, or not-for-profit sectors.

\section{Regulatory Statement}

This study was conducted in accordance with all the provisions of the local human subjects oversight committee guidelines and policies of: The research was conducted "in vitro" and did not involve any humans or animals, therefore, there was no need for registration and etic control.

\section{REFERENCES}

1. van Noort R. The future of dental devices is digital. Dent Mater. 2012;28(1):3-12. http://dx.doi.org/10.1016/j.dental.2011.10.014. PMid:22119539.

2. Baroudi K, Ibraheem SN. Assessment of chair-side computeraided design and computer-aided manufacturing restorations: a review of the literature. J Int Oral Health. 2015;7(4):96-104. PMid:25954082

3. Alghazzawi TF. Advancements in CAD/CAM technology: options for practical implementation. J Prosthodont Res. 2016;60(2):72-84. http://dx.doi.org/10.1016/j.jpor.2016.01.003. PMid:26935333

4. Revilla-León M, Özcan M. Additive manufacturing technologies used for processing polymers: current status and potential application in prosthetic dentistry. J Prosthodont. 2019;28(2):14658. http://dx.doi.org/10.1111/jopr.12801. PMid:29682823.

5. Joda T, Zarone F, Ferrari M. The complete digital workflow in fixed prosthodontics: a systematic review. BMC Oral Health. 2017;17(1):124. http://dx.doi.org/10.1186/s12903-017-0415-0. PMid:28927393.

6. Logozzo S, Franceschini G, Kilpela A, Caponi M, Governi L, Blois L. A comparative analysis of intraoral 3D digital scanners for restorative dentistry. J Med Technol. 2008;5:1-18.

7. Yuzbasioglu E, Kurt H, Turunc R, Bilir H. Comparison of digital and conventional impression techniques: evaluation of patients' perception, treatment comfort, effectiveness and clinical outcomes. BMC Oral Health. 2014;14(1):10. http://dx.doi. org/10.1186/1472-6831-14-10. PMid:24479892.

8. Sawase T, Kuroshima S. The current clinical relevancy of intraoral scanners in implant dentistry. Dent Mater J. 2020;39(1):57-61. http://dx.doi.org/10.4012/dmj.2019-285. PMid:31723067.

9. Logozzo S, Zanetti EM, Franceschini G, Kilpelä A, Mäkynen A. Recent advances in dental optics - Part I: 3D intraoral scanners for restorative dentistry. Opt Lasers Eng. 2014;54:203-21. http:// dx.doi.org/10.1016/j.optlaseng.2013.07.017.

10. Patzelt SB, Lamprinos C, Stampf S, Att W. The time efficiency of intraoral scanners: an in vitro comparative study. J Am Dent Assoc. 2014;145(6):542-51. http://dx.doi.org/10.14219/ jada.2014.23. PMid:24878708.

11. Beuer F, Schweiger J, Edelhoff D. Digital dentistry: an overview of recent developments for CAD/CAM generated restorations. Br Dent J. 2008;204(9):505-11. http://dx.doi.org/10.1038/ sj.bdj.2008.350. PMid:18469768.

12. Petrovic V, Gonzalez JVH, Ferrando OJ, Gordillo JD, Puchades JRB, Griñan LP. Additive layered manufacturing: sectors of industrial application shown through case studies. Int J Prod Res. 2011;49(4):1061-79. http://dx.doi. org/10.1080/00207540903479786.

13. Koch GK, Gallucci GO, Lee SJ. Accuracy in the digital workflow: from data acquisition to the digitally milled cast. J Prosthet Dent. 2016;115(6):749-54. http://dx.doi.org/10.1016/j. prosdent.2015.12.004. PMid:26803173. 
14. Patzelt SB, Emmanouilidi A, Stampf S, Strub JR, Att W. Accuracy of full-arch scans using intraoral scanners. Clin Oral Investig. 2014;18(6):1687-94. http://dx.doi.org/10.1007/s00784-0131132-y. PMid:24240949.

15. Bosch G, Ender A, Mehl A. A 3-dimensional accuracy analysis of chairside CAD/CAM milling processes. J Prosthet Dent. 2014;112(6):1425-31. http://dx.doi.org/10.1016/j. prosdent.2014.05.012. PMid:24993373

16. Schmitz TL, Ziegert JC, Canning JS, Zapata R. Case study: a comparison of error sources in high-speed milling. Precis Eng. 2008;32(2):126-33. http://dx.doi.org/10.1016/j. precisioneng.2007.06.001.

17. Berman B. 3-D printing: the new industrial revolution. Bus Horiz. 2012;55(2):155-62. http://dx.doi.org/10.1016/j. bushor.2011.11.003.

18. Javaid M, Haleem A. Current status and applications of additive manufacturing in dentistry: a literature-based review. J Oral Biol Craniofac Res. 2019;9(3):179-85. http://dx.doi.org/10.1016/j. jobcr.2019.04.004. PMid:31049281.

19. Braian $M$, Jimbo $R$, Wennerberg $A$. Production tolerance of additive manufactured polymeric objects for clinical applications. Dent Mater. 2016;32(7):853-61. http://dx.doi.org/10.1016/j. dental.2016.03.020. PMid:27118595.

20. Loflin WA, English JD, Borders C, Harris LM, Moon A, Holland JN, et al. Effect of print layer height on the assessment of 3D-printed models. Am J Orthod Dentofacial Orthop. 2019;156(2):283-9. http://dx.doi.org/10.1016/j. ajodo.2019.02.013. PMid:31375239.

21. Zhang ZC, Li PL, Chu FT, Shen G. Influence of the threedimensional printing technique and printing layer thickness on model accuracy. J Orofac Orthop. 2019:80(4):194-204. http:// dx.doi.org/10.1007/s00056-019-00180-y. PMid:31172199.

22. Chockalingam K, Jawahar N, Chandrasekhar U. Influence of layer thickness on mechanical properties in stereolithography. Rapid Prototyping J. 2006;12(2):106-13. http://dx.doi. org/10.1108/13552540610652456

23. International Organization for Standardization. Accuracy (trueness and precision) of measurement methods and results - Part 1: General principles and definitions. 1st ed. Geneve: ISO; 1994.

24. Kim SY, Lee SH, Cho SK, Jeong CM, Jeon YC, Yun MJ, et al. Comparison of the accuracy of digitally fabricated polyurethane model and conventional gypsum model. J Adv Prosthodont. 2014;6(1):1-7. http://dx.doi.org/10.4047/jap.2014.6.1.1. PMid:24605199

25. Cho SH, Schaefer O, Thompson GA, Guentsch A. Comparison of accuracy and reproducibility of casts made by digital and conventional methods. J Prosthet Dent. 2015;113(4):310-5. http:// dx.doi.org/10.1016/j.prosdent.2014.09.027. PMid:25682531.

26. Al-Imam H, Gram M, Benetti AR, Gotfredsen K. Accuracy of stereolithography additive casts used in a digital workflow. J Prosthet Dent. 2018;119(4):580-5. http://dx.doi.org/10.1016/j. prosdent.2017.05.020. PMid:28781073

27. Sim JY, Jang Y, Kim WC, Kim HY, Lee DH, Kim JH. Comparing the accuracy (trueness and precision) of models of fixed dental prostheses fabricated by digital and conventional workflows. J Prosthodont Res. 2019;63(1):25-30. http://dx.doi.org/10.1016/j. jpor.2018.02.002. PMid:29615324.

28. Keating AP, Knox J, Bibb R, Zhurov Al. A comparison of plaster, digital and reconstructed study model accuracy. J Orthod. 2008;35(3):191-201. http://dx.doi. org/10.1179/146531207225022626. PMid:18809782

29. Kasparova M, Grafova L, Dvorak P, Dostalova T, Prochazka A, Eliasova $H$, et al. Possibility of reconstruction of dental plaster cast from 3D digital study models. Biomed Eng Online.
2013;12(1):49. http://dx.doi.org/10.1186/1475-925X-12-49. PMid:23721330.

30. Camardella LT, Vilella OV, van Hezel MM, Breuning KH. Accuracy of stereolithographically printed digital models compared to plaster models. J Orofac Orthop. 2017;78(5):394-402. http:// dx.doi.org/10.1007/s00056-017-0093-1. PMid:28361165.

31. Jin SJ, Kim DY, Kim JH, Kim WC. Accuracy of dental replica models using photopolymer materials in additive manufacturing: in vitro three-dimensional evaluation. J Prosthodont. 2019;28(2):e55762. http://dx.doi.org/10.1111/jopr.12928. PMid:29968424.

32. Park ME, Shin SY. Three-dimensional comparative study on the accuracy and reproducibility of dental casts fabricated by $3 D$ printers. J Prosthet Dent. 2018:119(5):861.e1-7. http://dx.doi. org/10.1016/j.prosdent.2017.08.020. PMid:29475753.

33. Patzelt SB, Bishti S, Stampf S, Att W. Accuracy of computeraided design/computer-aided manufacturing-generated dental casts based on intraoral scanner data. J Am Dent Assoc. 2014;145(11):1133-40. http://dx.doi.org/10.14219/jada.2014.87. PMid:25359645

34. Yau HT, Yang T, Lin Y. Comparison of 3-D printing and 5-axis milling for the production of dental e-models from intra-oral scanning. Comput Aided Des Appl. 2016;13(1):32-8. http:// dx.doi.org/10.1080/16864360.2015.1059186.

35. Jeong YG, Lee WS, Lee KB. Accuracy evaluation of dental models manufactured by CAD/CAM milling method and 3D printing method. J Adv Prosthodont. 2018;10(3):245-51. http://dx.doi. org/10.4047/jap.2018.10.3.245. PMid:29930795.

36. Choi JW, Ahn JJ, Son K, Huh JB. Three-dimensional evaluation on accuracy of conventional and milled gypsum models and 3d printed photopolymer models. Materials. 2019;12(21):3499. http://dx.doi.org/10.3390/ma12213499. PMid:31731447.

37. Alharbi N, Alharbi S, Cuijpers VMJI, Osman RB, Wismeijer D. Three-dimensional evaluation of marginal and internal fit of 3D-printed interim restorations fabricated on different finish line designs. J Prosthodont Res. 2018;62(2):218-26. http://dx.doi. org/10.1016/j.jpor.2017.09.002. PMid:29032176.

38. Mai HN, Lee KB, Lee DH. Fit of interim crowns fabricated using photopolymer-jetting 3D printing. J Prosthet Dent. 2017;118(2):208-15. http://dx.doi.org/10.1016/j. prosdent.2016.10.030. PMid:28089333.

39. Lee WS, Lee DH, Lee KB. Evaluation of internal fit of interim crown fabricated with CAD/CAM milling and $3 D$ printing system. J Adv Prosthodont. 2017;9(4):265-70. http://dx.doi. org/10.4047/jap.2017.9.4.265. PMid:28874993.

40. Homsy FR, Özcan M, Khoury M, Majzoub ZAK. Marginal and internal fit of pressed lithium disilicate inlays fabricated with milling, 3D printing, and conventional technologies. J Prosthet Dent. 2018;119(5):783-90. http://dx.doi.org/10.1016/j. prosdent.2017.07.025. PMid:28969918.

41. Jang Y, Sim JY, Park JK, Kim WC, Kim HY, Kim JH. Accuracy of 3-unit fixed dental prostheses fabricated on 3D-printed casts. J Prosthet Dent. 2020;123(1):135-42. http://dx.doi.org/10.1016/j. prosdent.2018.11.004. PMid:31027960.

42. Pompa G, Carlo S, Angelis F, Cristalli MP, Annibali S. Comparison of conventional methods and laser-assisted rapid prototyping for manufacturing fixed dental prostheses: an in vitro study. BioMed Res Int. 2015;2015:318097. http://dx.doi. org/10.1155/2015/318097. PMid:26576419.

43. Khaledi AA, Farzin M, Akhlaghian M, Pardis S, Mir N. Evaluation of the marginal fit of metal copings fabricated by using 3 different CAD-CAM techniques: milling, stereolithography, and 3D wax printer. J Prosthet Dent. 2020;124(1):81-6. http://dx.doi. org/10.1016/j.prosdent.2019.09.002. PMid:31672421.

44. Presotto AGC, Barão VAR, Bhering CLB, Mesquita MF. Dimensional precision of implant-supported frameworks fabricated by $3 D$ 
printing. J Prosthet Dent. 2019;122(1):38-45. http://dx.doi. org/10.1016/j.prosdent.2019.01.019. PMid:30922558.

45. Viegas DC, Mourão JT, Roque JC, Riquieri H, Fernandes J, Arrobas $F$, et al. Evaluation of the influence of the impression technique, scanning direction and type of scanner on the accuracy of the final model. Braz Dent Sci. 2021;24(1):1-13. http://dx.doi. org/10.14295/bds.2021.v24i1.2179.

46. Hair JF, Black WC, Babin BJ, Anderson RE, Tatham RL. Multivariate Data Analysis. 7th ed. Edinburgh: Pearson New Internacional Edition; 2005

47. Cohen J. Statistical power analysis for the behavioural sciences. 2nd ed. New York: Academic Press; 1988.

48. Faul F, Erdfelder E, Buchner A, Lang AG. Statistical power analyses using G*Power 3.1: tests for correlation and regression analyses. Behav Res Methods. 2009;41(4):1149-60. http://dx.doi. org/10.3758/BRM.41.4.1149. PMid:19897823.

49. Menditto A, Patriarca M, Magnusson B. Understanding the meaning of accuracy, trueness and precision. Accredit Qual
Assur. 2007;12(1):45-7. http://dx.doi.org/10.1007/s00769-0060191-z.

50. 3Shape A/S. Trios 3 [Internet]. Copenhagen: 3Shape A/S; 2020 [cited 2020 oct 10]. Available from: https://www.3shape.com/ en/scanners/trios-3.

51. Medina-Sotomayor P, Pascual-Moscardó A, Camps I. Relationship between resolution and accuracy of four intraoral scanners in complete-arch impressions. J Clin Exp Dent. 2018;10(4):e361-6. http://dx.doi.org/10.4317/jced.54670. PMid:29750097.

52. Anusavice K. Phillips' science of dental materials. 11th ed. St. Louis: Elsevier; 2003. p. 223-30.

53. Anusavice K. Phillips' science of dental materials. 11th ed. St. Louis: Elsevier; 2003. p. 273-6.

54. Zirkonzhan. Scaner S600 Arti [Internet]. Copenhagen: Zirkonzhan; 2020 [cited 2021 may 30]. Available from: https:// zirkonzahn.com/pt/sistemas-cad-cam/scanner-s600-arti.

Diogo Miguel da Costa Cabecinha Pacheco Viegas

(Corresponding address)

Lisbon Dental School, Lisboa, Portugal.

Date submitted: 2021 March 20

Email address: dviegas@campus.ul.pt Accept submission: 2021 June 26 